\title{
Editorial
}

\section{O papel dos periódicos científicos na circulação de ideias}

\section{Marcelo Lambach} marcelolambach@gmail.com orcid.org/0000-0001-7168-5498 Universidade Tecnologica Fede do Paraná (UTFPR), Curitiba, Paraná, Brasil
Para discutir brevemente sobre o papel dos periódicos científicos na circulação de ideias, parte-se da compreensão epistemológica de Ludwik Fleck (2010), de que a constituição do conhecimento é um fato coletivo. Ou seja, tratase de uma epistemologia sociológica, uma "Teoria Sociológica do Conhecimento" (SCHNELLE, 1986, p. 262) ou, ainda, uma "Sociogênese do Conhecimento" (DELIZOICOV et al., 2002).

Com esse entendimento, Fleck sustenta que conhecimento é uma atividade social por excelência e não uma ação que se localiza integralmente dentro dos limites do indivíduo. Ou seja, o conhecimento "está intimamente ligado a pressupostos e condicionamentos sociais, históricos, antropológicos e culturais e, à medida que se processa, transforma a realidade" (DELIZOICOV et al., 2002, p. 53).

Então, conhecer, para Fleck, quer dizer "constatar os resultados impostos por certas pressuposições dadas". Com isso,

A frase "alguém conhece algo" exige um suplemento análogo, por exemplo:
"sobre a base de um estado determinado de conhecimento"; ou melhor,
"como membro de um meio cultural determinado"; ou ainda melhor, "em um
estilo de pensamento determinado, em um determinado coletivo de
pensamento". (FLECK, 1986, p. 86).

Para Fleck, o sujeito que participa do processo de constituição do conhecimento é um sujeito coletivo que compartilha práticas, concepções, tradições e normas características ou próprias de um coletivo, ou seja, ele pertence a um Coletivo de Pensamento (CP) que possui Estilo de Pensamento (EP) próprio.

A partir dessa ótica, parece ser inconcebível a ideia de que a produção do conhecimento científico ocorre de forma neutra. Ou seja, é inaceitável o indutivismo empirista ingênuo, uma vez que "a observação livre de pressuposições, é psicologicamente um absurdo e logicamente uma brincadeira" (FLECK, 1986, p. 138). Do mesmo modo, será inadmissível pensar que não seja afetada por elementos e interesses externos ao da pesquisa, como foi evidenciado por Fleck, ao tomar como exemplo a reação de Wassermann como um método de análise clínica para determinação da sífilis, e dizer: 
populi [voz do povo], articulada por um alto funcionário do ministério. (FLECK, 2010, p. 114).

Para Fleck a existência do EP depende da constituição de um coletivo, sendo que esse não é uma simples soma de indivíduos. Cada indivíduo pertencente a um CP que geralmente não tem consciência do estilo de pensamento que direciona o seu olhar. Fleck (1986) argumenta que isso ocorre pela absoluta coerção que o coletivo exerce sobre seu pensamento, e "contra a qual qualquer contradição é simplesmente impensável” (FLECK, 2010, p. 84).

Fleck parte do princípio de que um CP se constitui "sempre que duas pessoas trocam ideias" (FLECK, 1986, p. 90), portanto ele

$$
\begin{aligned}
& \text { consiste em indivíduos diferentes, tendo também sua forma psíquica } \\
& \text { particular e regras particulares de comportamento. Em sua totalidade, ela é } \\
& \text { até mais estável e mais coerente que o chamado indivíduo, que se constrói a } \\
& \text { partir de impulsos contraditórios. (FLECK, 2010, p. 87). }
\end{aligned}
$$

Assim, a constituição do conhecimento é um fato coletivo, que se altera na medida em que novos indivíduos, pertencentes a distintos $\mathrm{CP}$ e com seus próprios $E P$, passam a integrar o coletivo. E, ainda, que os fatos científicos são "assimilados e estilizados, ou seja, traduzidos em seu próprio estilo por outros coletivos de pensamento" (DELIZOICOV, et al., 2002, p. 59).

Levando-se em conta que os indivíduos podem pertencer, simultaneamente, a mais de um círculo esotérico e exotérico, Fleck propõe que tal fato faz ocorrer a circulação de ideias, afirmando que "a estrutura emaranhada da sociedade moderna faz com que os coletivos de pensamento se entrecruzem e se relacionem muitas vezes espacial e temporalmente" (FLECK, 1986, p. 154).

Como cada coletivo que constitui um círculo esotérico (de especialistas onde a coerção é mais intensa) possui um EP próprio, para mantê-lo os participantes passam a utilizar processos mais ou menos coercitivos, por meio da Circulação Intracoletiva de Ideias, reforçando os laços entre os componentes do CP, formando novos integrantes que passarão a compartilhar o mesmo EP.

Já para a disseminação do EP do círculo Esotérico para os círculos Exotéricos (aqueles que se estabelecem em torno do círculo esotérico e consomem a sua produção científica), ocorre a Circulação Intercoletiva de Ideias, que pressupõe a introdução de novas ideias de um CP em outro com seu EP instaurado.

Em relação a essa circulação de ideias, Alvetti e Cutolo (2005, p. 2) apontam que é possível identificar as "articulações com o processo da comunicação científica, em particular, no processo de disseminação científica", quer intrapares, ou seja, entre especialistas da mesma área do conhecimento ou áreas afins, ou extrapares, para especialistas fora da área de conhecimento do objeto da disseminação. Como destaca Fleck, "a palavra impressa, o cinema e o rádio possibilitam o efeito intelectual recíproco dentro da comunidade de pensamento 
e a coesão entre os círculos esotéricos e exotéricos, apesar das distâncias e da falta de circulação de pessoas" (FLECK, 2010, p. 159).

De acordo ainda com Alvetti e Cutolo (2005, p.3), "no caso da disseminação científica intrapares, temos a circulação de ideias nos círculos esotéricos de especialistas, e na disseminação extrapares, por sua vez, a circulação nos diversos círculos exotéricos de especialistas".

Dessa forma, os periódicos científicos, como é o caso da ACTIO, possibilitam a disseminação intercoletiva de novas compreensões sobre as relações entre o Sujeito, o Objeto e o Conhecimento. A ACTIO firma, assim, a responsabilidade de divulgar o conhecimento e submetê-lo aos diálogos necessários da sociedade. E, ao mesmo tempo, a partir da circulação intracoletiva de ideias, contribui para consolidar o estilo de pensamento vigente, cuja importância se reflete até no diaa-dia dos cidadãos, chegando, como diz Fleck (2010, p. 70), a invadir a vida cotidiana e as expressões verbais, e ao se internalizar e se tornar literalmente um ponto de vista para os sujeitos, qualquer contradição a ele parece ser impensável e impraticável.

\section{REFERÊNCIAS}

ALVETTI, M.; CUTOLO, L. R. A. Uma visão epistemológica da circulação de ideias presente na comunicação científica. In: SIMPÓSIO NACIONAL DE ENSINO DE Fí́SICA, 2005, Rio de Janeiro. Anais... Rio de Janeiro. p. 1-4. Disponível em: <http://www.sbf1.sbfisica.org.br/eventos/snef/xvi/cd/>.

DELIZOICOV, D. et al. Sociogênese do Conhecimento e Pesquisa em Ensino: Contribuições a partir do Referencial Fleckiano. Caderno Brasileiro de Ensino de Física, Florianópolis: UFSC, v. 19, número especial, p. 52-69, jun. 2002.

FLECK, L. La Génesis y el Desarrollo de un Hecho Científico. Madrid: Alianza Editorial, 1986.

Gênese e desenvolvimento de um fato científico. Belo Horizonte: Fabrefactum, 2010.

SCHNELLE, T. Ludwik Fleck and the Philosophy of Lwów. In: COHEN, R. S.; SCHNELLE, T. Cognition and Fact: Materials on Ludwik Fleck. Dordercht: Reidel, 1986, p. 231-265.

Recebido: 15 dez. 2017

Aprovado: 22 dez. 2017

DOI: 10.3895/actio.v2n3.7536

Como citar: LAMBACH, M. O papel dos periódicos científicos na circulação de ideias. ACTIO, Curitiba, v.

2, n. 3, p. 1-3, out./dez. 2017. Disponível em: <https://periodicos.utfpr.edu.br/actio>. Acesso em: XXX.

Correspondência:

Marcelo Lambach

Rua Dep. Heitor de Alencar Furtado, 5000 - BI.C - Bairro Ecoville - CEP 81280-340 - Curitiba, Paraná, Brasil.

Direito autoral: Este artigo está licenciado sob os termos da Licença Creative Commons-Atribuição 4.0 Internacional.

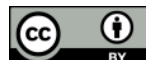

